\title{
RTNS-II 1984 Annual Report
}

Joint U.S.-Japan Sponsorship

UCID--19837-84

DEB7 014281

\section{DISCLAIMER}

\begin{abstract}
This report was prepared as an account of work sponsored by an agency of the United Siates Government. Neilher the Unized States Government nor any agency thereor, nor any of their employes, makes any warranty, express or implied, or assumes any legal liability or responsibility for the accuracy, completeness, or usefulness of any informatiun, apparatus, product, or process disclosed, or represents that its use would nat infringe privately owned rights. Reference herein to any specific commerciel producl, process, or tervice by trade name, trademark, minufacturer, or otherwise does nol necesserily constitute or imply its endorsement, recommendation, or favoring by the Uniled Slates Government of eny afency thereor. The viewt and opinions of aulhors expressed herein do not necosserily state or reflect those of the United States Governunent or any agency thereof.
\end{abstract}

\begin{abstract}
About the Cover
We are analyzing miniature tensile sp:cimens irradiated at the RTNS-II to study the mechanical property clanges that are induced by $14-\mathrm{MeV}$ neutrons. The dimensions of the specimen shown are $12.7 \times 2.34 \times 0.25 \mathrm{~mm}$. The two graphs appeaning beneath the specimen plot tensile data for annealed Marz-grade copper irradiated at $90^{\circ} \mathrm{C}$. The graph to the ieft traces stress-strain curves for unirradiated copper (lo:ver curve) and for copper irradiated to a fluence of $1.4 \times 10^{15} \mathrm{n} / \mathrm{cm}^{2}$. The bottom right graph shows how copper's $0.2 \%$-offset yield stress changes as a function of $14-\mathrm{MeV}$ neutron fluence. Tr study the effects of the difference in neutron energies, we are now companing the tensile property ch.nges of materials irradiated here at elevated temperatures with those irradiated under the same conditions at the Omega West Reactor at Los Alamos National l aboratory.
\end{abstract}




\section{Foreword*}

This is the third annual report summarizing irradiation experinents at RTNS-II. It covers calendar ycar 1983, and includes reports of all irradiation results, both fusion and non-fusion related. These comprise both secondary (or "add-on") and primary irradiations.

Each summary article has been submitted by the investigator and has been altered only to meet the style and format requirements of this report. Previous information concerning irradiations and the facility are contained in the RTNS-II 1982 Annial Report (UCID-19837-82). RTNS-II 1983 Annual Report (UCID19837-83), and the Guide for Experimenters (LLLN-M-1994 Rev: 1, March, 1982).

Dale W. Hejkkinen

Deputy Facility Manager, RTNS-II

:Work performed under the auspices of the U.S. Departmenl of Energy and the Japan Ministry of Education, Science and Cullute (Monibusho) by the Lawrence Livermare National Laboratory under contrast number W-zA05-ENG-48. 


\section{Contents}

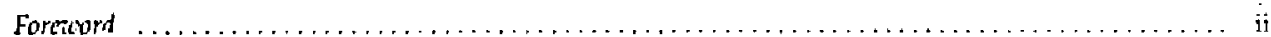

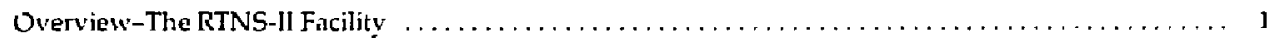

(D. W. Heikkinan)

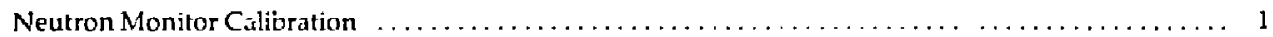

(D. W. Heikkinen)

Japan-Initiated Fission Expreriments

14-MeV Neutron Irradiation Hardening in Metals, Allọss, and Other Materials

(K. Abe)

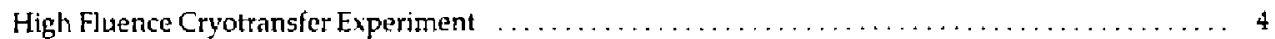

(H. Matsui, S. Iwasaki, M. W. Guinan, and). S. Huang)

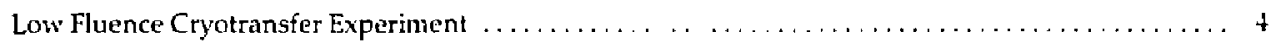

(Y. Shimomura and M. W. Guinan)

Secondary Defect Formatior: in Copper by 14-MeV Neutron Irradiation

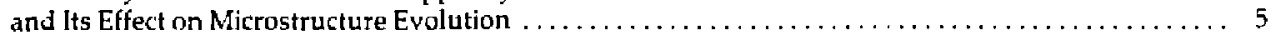

(N. Yoshida, Y. Akashi, K. Kitajima, and M. Kiritani)

Defect-Structure Evolution after Radiation Damage from DT Fusion Neutrons . . . . . . . . . . . 5

(M. Kiritani)

14.8.MeV Neutron-lnduced Activation in Some Netals and Practical Alloys $\ldots \ldots \ldots \ldots \ldots \ldots .6$

(K. Saneyoshi and K. Abe)

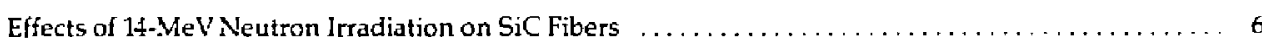

(K. Ckamura, T. Matsuzawa, M. Sato, K. Sumita, and T. Iida)

\section{U.S. -Intiated Fusion Experiments}

Permeation of ${ }^{1} \mathrm{~N}$-Labeled Gas Molecules Through Semi-Permeable Membranes $\ldots \ldots \ldots \ldots \ldots, 7$ (R. A. Jalbert)

Spinel Swelling after Low-Dose Neutron Irradiation $\ldots \ldots \ldots \ldots \ldots \ldots \ldots \ldots \ldots \ldots \ldots \ldots$

(W. A. Coghlan, F. W. Clinard, Jr., N. 1toh, and L. R. Greenwcod)

Hardening of Instrument Channel Components for Fusion Radiation Environments $\ldots \ldots \ldots \ldots .8$ (C. P. Cannon)

Fusion-Neutron Irradiation of $\mathrm{Nb}_{3} \mathrm{Sn}-\mathrm{Ti}$ Alloy Superconductors $\ldots \ldots \ldots \ldots \ldots \ldots \ldots \ldots \ldots$

(C. L. Snead, Jr. and M. W. Guinan)

Measurement of $14-\mathrm{MeV}$ Cross Sections $\ldots \ldots \ldots \ldots \ldots \ldots \ldots \ldots \ldots \ldots \ldots \ldots \ldots \ldots$

(R. K. Smither, L. R. Greenwood, D. G. Doran, and H. L. Heinisch)

Low-Exposure Spectral-Effects Experiment $\ldots \ldots \ldots \ldots \ldots \ldots \ldots \ldots \ldots \ldots \ldots \ldots \ldots$

(H. L. Heinisch) 
An Intercomparison Exetcise Using Irradiated Nickel Foils 11 (R. C. Haight)

Production of ${ }^{74} \mathrm{As}, \overline{\bar{K}}_{\mathrm{K}}$, and ${ }^{123}$ Xe by $(\mathrm{n}, 2 \mathrm{n})$ Reactions: Cross Sections and Decay Properties ....... 11 (P. Pawlikowski, G. Coleman, and C. F. Smith)

Production of ${ }^{120 \mathrm{~m}} \mathrm{Sb}$

(N. L. Smith)

Residence-Time Distribution of Oil Shale Particles in a Fluidized Bed

(L. M. Lucht and D. Nelson)

14-MeV Neutron Sensitivity of Uranium Fission-Based Neutron Detectors

(M. J. Moran and D. L. Redhead)

Fareign Experiments

Fusion-Neutron Irtadiation of Multifilamentary $\mathrm{Nb}_{3} \mathrm{Sn}$ Alloy Superconductors (R. Flükiger and M. W. Guinan)

Neutron Irradiation of Superconductors and the Damage-Energy

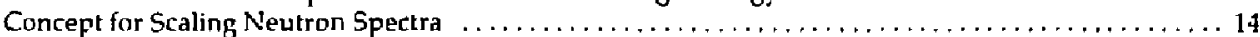
(P. A. Hahn, H. W. Weber, M. W. Guinan, L. R. Greenwood, R. C. Birtcher, and B. S. Brown) 


\title{
Overview-The RTNS-II Facility
}

Early in 1982 a unifue collaboration began between the governments of Japan and the United States. At that time the U.S. Department of Energy (DOE) and the Japan Ministry of Education, Science, and Culture (Monbusho) agreed jointly to support the operation and development of RTNS-II, and to share in its utilization.

RTNS-II was built to provide a detterium-tritium neutron snurce for the study of fusion neutron effects. In the quest to apply fusion to comnercial powror production, the specific mission of RTNS-II is threetold:

- To acquire direct enginesring data for near-tern conlinement experiments and for materials that will see moderate geutron dose in future reactor syslems.

- To measure production rates of trensmutints and to develop appropriate radiation-resistant instrumentation for fusion systens.

- To study the radiation-induced property changes caused by fusion neutrons.

RTNS-Il comprises two independeni suurces of $14-\mathrm{MeV}$ neutrons. Detterium tons are extracted from the ion source at $30 \mathrm{keV}$. $\mathrm{O}^{-}$ions are selected by a $90-\mathrm{deg}$ bending magnet. The air-insulated terminal is held at roughly $340 \mathrm{keV}$ by a Cockroft-Walton power supply. We now deliver $130 \mathrm{~mA}$ of roughly $370-\mathrm{keV}$ deuterons to the target in a beam spot size about $1 \mathrm{~cm}$ in diancter. This provides a neutron source strength approaching $4 \times 10^{\text {l3 }} \mathrm{n} / \mathrm{s}$. The nominal operating sched ule is 24 hours a day, 5 days a week.

The rotating target has a titanium-tritide soating on a copper alloy substrate. This material would thermally decompose at an unacceptable rate if its temperature were allowed to rise above about $300^{\circ} \mathrm{C}$. Thus. to limit the peak temperature produced by beam heating, the target rotates at $5000 \mathrm{rpm}$ and is intensively cooled by chilled water flowing through internal chanrels. An air-levitated, ditferentially pumped vacuum seal pernits target-assembly rotation with negligible leakage of air into the vacuum system.

Weeting the materials challenges of fusion systems requires that we use a broad array of research tools. In this context, RTNS-JI has a unique role. It is the worid's only 14-MeV-neutron source dedicated exclusively to materials reseach.

\section{Neutron Monitor Calibration}

\author{
D. W. Heikkinen \\ Lawrence Livermure National Laboratory, Livermore, CA
}

To provide instantaneous and cumulative data on nelutron production for the RTNS-Il neutron sources, neutrons are monitored using proton-recoil counters arid ionization chambers. These data also provide the time history of an irradiation which is useful for obtaining neutron fluenıes from dosimetry.

The neutron production monitors are periodically calibrated by placing niobium dosimetry foils on the front surface of the individual monitors. Repeated calibrations have shown no large changes in the calibration constants.

All neutron munitor calibration records are maintained at the RTNS-ll facility.

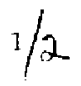




\section{RTNS-II}

\section{Japan-Initiated \\ Fusion Experimients}
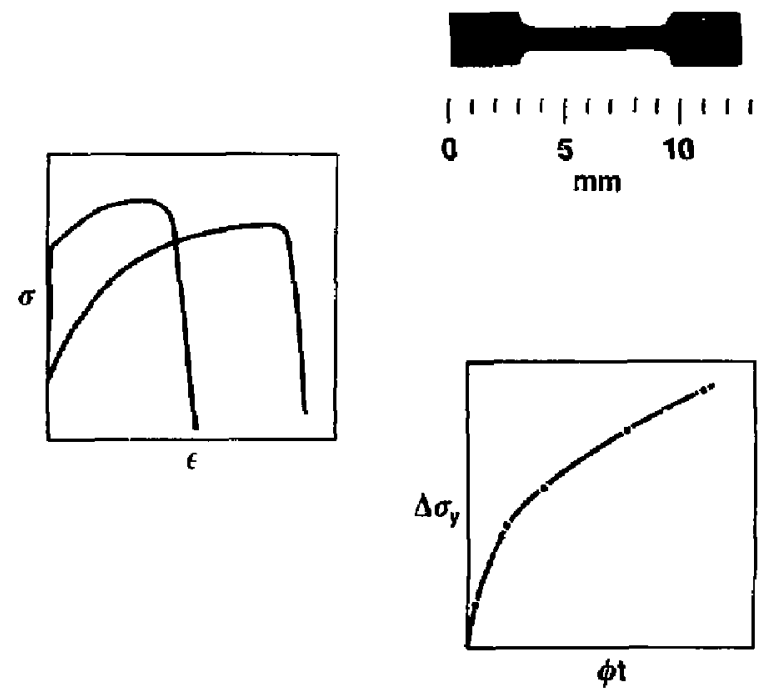

FEPRODUCED FROM

BEST AVALLABLE COPY 


\title{
14-MeV Neutron Irradiation Hardening in Metals, Alloys, and Other Materials
}

\author{
Katsunori Abe \\ The Research Institute for Iron, Steel, and Other Metals \\ Tohoku University, Sendai 980, Japan
}

A total of 2300 specimens, including tensile specimens and transmission electron microscopy (TEM) disks, were irradiated at room temperature by the RTNS-II. These specimens, which have been supplied from sixteen material research groups in Japan, include: (a) pure metals and their alloys $(\mathrm{Al}, \mathrm{Al}-\mathrm{Si}, \mathrm{Ti}, \mathrm{V}$, $\mathrm{V}-\mathrm{C}, \mathrm{V}-\mathrm{Ti}, \mathrm{V}-\mathrm{Fe}, \mathrm{V}-\mathrm{Co}, \mathrm{V}-\mathrm{B}, \mathrm{Fe}, \mathrm{Ni}, \mathrm{Ni}-\mathrm{Si}, \mathrm{Cu}, \mathrm{Zr}, \mathrm{Nb}, \mathrm{Mo}, \mathrm{Ag}, \mathrm{Au}$ ); (b) fusion-oriented practical alloys (AI$\mathrm{Mg}$-Li, SUS 304, SUS 316, JPCA, Ferritics, V-20Ti, TZM); (c) amorphous metals $\left(\mathrm{Pd}_{80} \mathrm{Si}_{20}\right.$. Fe $\mathrm{F}_{80} \mathrm{~B}_{20}$, $\mathrm{Fe}_{78} \mathrm{Si}_{10} \mathrm{~B}_{12 r}, \mathrm{Zr}_{70} \mathrm{M}_{30,}, \mathrm{Zr}_{x} \mathrm{Cu}_{100-x}$ ); and (d) polyimide film (KAPTON). Three irradiations over a period of 11 weeks produced maximum fluences of $6 \times 10^{18} \mathrm{n} / \mathrm{cm}^{2}$ in TEM disks and $5 \times 10^{18} \mathrm{n} / \mathrm{cm}^{2}$ in tensile specimens. Duplicate sets of specimens were irradiated for fusion-fission correlation study at the Kyoto University Reactor (KUR).

Neutron-irradiation reseasch at LLNL can be divided into three main areas:

(j) Irradiation and Testing Apparatus.

(ii) Irradiation Hardening in Metals and Alloys.

(iii) Irradiation Damage in KAPTON polyimide.

A summary of our progress in these three areas follows.

\section{Miniature Specimen Material Testing}

A universal testing machine with temperature controller, a data analyser, and miniature specimen grips for tensile-, 3-point bend-and bulge-test were installed at LLNL. We used these facilities to correlate bend properties and microhardness with tensile properties for two metals, Mo and TZM, each one having been exposed to its own level of heat treatment and neutron fluence. This correlation enabled us to produce a wide range of stress levels.

\section{Irradiation Hardening in Metals and Alloys}

Hardening by $14-\mathrm{MeV}$ neutrons depends strongly on materials and their treatment. These may be divided into three groups:

(i) Negligible hardening: $\mathrm{Al}, \mathrm{Al}-\mathrm{Mg}$-Li alloy, and amorphous alloys.

(ii) Small hardening (less than 50\% hardening at $3 \times 10^{18} \mathrm{n} / \mathrm{cm}^{2}$ ): V, Mo, T2M, Ferritics, Fe-9Cr and Cu-Prop.

(iij) Large hardening (greater than $50 \%$ hardening at $3 \times 10^{18} \mathrm{n} / \mathrm{cm}^{2}$ ): $\mathrm{Fe}, \mathrm{Ni}, \mathrm{Au}, \mathrm{Cu}$, SUS 316 (JPC $\mathrm{A}$ ).

\section{Irradiation Damage of Kapton Polyimide Film}

Because of its relatively high jesistance to radiation damage, polyimide film may be used as an insulator for the fusion project's superconducting magnet. We measured the mechanical property changes that were included in KAPTON polyimide film by $14-\mathrm{MeV}$ neutrons and $\gamma$-rays using the miniature tensile technique [1], and found that elongation decreases severely with fluences ajove $10^{\mathrm{V}} \mathrm{n} / \mathrm{cm}^{2}$. Changes in optical absorption correspond well with elongation changes. Fusion neutrons cause $70 \times$ more damage than the equivalent $\gamma$-ray dose.

\section{Reference}

[1] K. Abe, K. Saneyoshi, C. M. Logan, and F. W. Clinard, Jr., "14-MeV-Neutron Irradiation Damage of KAPTON Polyimide Film," ICFRM-1 (1984, Tokyo), pp. 4-43. 


\title{
High Fluence Cryotransfer Experiment
}

\author{
H. Matsui and S. Iwasaki \\ Tohoku University, Sendai 980, Japan \\ M. W. Guinan and J. S. Huang \\ Lawrence Livermore National Laboratory, Livermore, CA
}

\begin{abstract}
We irradiated a capsule ceritaining 30 electrical-resistivity samples, 40 positron-onnihilation samiplas, 1200 transmission electron microscopy (TEM) foils, 1500 bend-test samples, and 140 tensile samples at $20 \mathrm{~K}$ fiom October 18 to November 8,1984 . The neutron fluence in the capsule varied from $3.5 \times 10^{16}$ to $1.4 \times 70^{18}$ $\mathrm{n} / \mathrm{cm}^{2}$. Following the irradiation, we transferred the sample capsule to a liquid nitrogen storage bath. where, without waming above $77 \mathrm{~K}$, the capsule was disessembled and ail dosimetry foils were removed. The specimens were then transferred to a long-term LN storage dewar.

The experimert exarined specimens supplied by 12 additional groups in Japan, representing Hiroshima, Hokkaido, Kyushu, Nagoya and Tohoku Universities, and the Iniversity of Tokyo. Included were: (a) pure metals and alloys of $\mathrm{Fe}, \mathrm{Ni}, \mathrm{Mo}, \mathrm{V}, \mathrm{Cu}$. Al, $\mathrm{Ti}, \mathrm{Ag}, \mathrm{Nb}, \mathrm{Mg}, \mathrm{Zr}$, and $\mathrm{Au}$; (b) austenitic and ferritic steels; (c) silicon and germanium semiconductors; and (d) amorphous metals.

After a short cooing poriod, samples for both bend and tensile tests were transferred without warming tc a medsuremunt cryostat. Mechanical-properties test 5 were carried out at temperatures ranging from $4.2 \mathrm{~K}$ to room temperature.

Only a few preliminary tests were completed in 1984 to validate the transfer operations, and the results of these tests will appear in journals in late 1985. For a more detailed discussion of this work, see Hideki Matsui, "Mechanical Properties of Metals and Alloys Irradiated with 14-MeV Neutrons at Low Temperatures," in the 1984 Anmual Research Reporf of Japanese Contributions for Japan-US Collaboration on RTNS-II Utilization, (Monbusho, Japan Fusion Cooperation Prograrn, March, 1985), pp. 55-75.
\end{abstract}

\section{Low Fluence Cryotrensfer Experiment}

\author{
Y. Shimomura \\ Faculty of Engineering, Hiroshima University, Shitami, Saijjō-chō, Gigashihirashima City 724, Japan \\ M. W. Guinan \\ Nuclear Chemistry Division, Lawrente Livermore National Laboratory, Livermore, CA
}

A capsule containing 28 electrical resistivity samples, 46 positron-annihilation samples, and 835 transmission electron microscopy (TEM) f́rils was irradiated at $20 \mathrm{~K}$ from March 12 to March 17, 2984. The neutron fluence in the capsule varied from 0.6 to $12.8 \times 10^{20} \mathrm{n} / \mathrm{m}^{2}$. Following the irradiation, the sample capsule was translerred to a liquid nitrogen storage bath. Without warming above $77 \mathrm{~K}$, the capsule was disassembled, its dosimetry foils were removed, and the specimens were then transferred to a long-term LN storage dewar.

The experiment examined specimens supplied by 20 additional investigators in Japan, representing Hokkaido. Kyoto, Hiroshima and Kyushu Universities, and the Universittes of Tokyo and Osaka. Iricluded were: (a) pure metals and alloys of $\mathrm{Fe}, \mathrm{Mo}, \mathrm{V}, \mathrm{Ni}, \mathrm{Au}, \mathrm{Ta}, \mathrm{Ti}, \mathrm{Al}, \mathrm{Cu}, \mathrm{Zr}, \mathrm{Ag}, \mathrm{Pt}$, and $\mathrm{Nb}$; (b) ferritic and austenitic steels; (c) germanium, silicon, and gallium arsenide semiconductors; (d) $\mathrm{Cu}_{3} \mathrm{Au}, \mathrm{Nb}_{3} \mathrm{SrI}$, $\mathrm{Nb}_{3} \mathrm{Ce}, \mathrm{V}_{3} \mathrm{Ge}$ ordered alloys; and (e) silicon carbides and nitrides.

Specimens were successfully shipped to Japan at $L N$ temperatures and subsequently transferred witl. out warming to the positron-annihilation and TEM stages. TEM transfers were also made at LLNL.

At this time only some preliminary TEM observations have been presented at the First Inteniational Mecting on Fusion Retactor Materials in Tokyo, December 3-6, 1984. This paper has been subnitted to J. Nucl. Mat. by Y. Shimomura, M. W. Gujnan, and M. Kiritani, under the title "Low Temperature DT Neutron Irradiation and Cryotranster Observation of Cascade Defects in Metals." 


\title{
Secondary Defect Formation in Copper by 14-MeV Neutron Irradiation and Its Effect on Microstructure Evolution
}

\author{
N. Yoshida, Y. Akashi, and K. Kitajima \\ Research Instifute for Applied Mechanics, Kyushu University, Kasuga 816, Japan \\ M. Kiritani \\ Faculty of Engineering, Hokkaido University, Sapporo 060, Japan
}

One of the typical features of $14-\mathrm{MeV}$-neutron irraciation is that the average primary knock-on energy reaches a few hundred keV in most materials, so that the high transfer energy of a singte collision creates a cascade of several hundreds of point defects in a small region. The deferts are successively rearranged and some of them form clusters. Though it has long been recognized that the rearrangement of a cascade is essential for damage-structure evolution under energetic particle irradiation (such as irradiation by 14$\mathrm{MeV}$ neutrons), up to now its fundamental aspects have not been investigated well enough to understand the atomic processes of damage-structure evolution.

The purpose of the present work, then, is to reveai the rearrangement processes of lattice defects in a high-eneroy (14-MeV-neutron) cascade, and to understand the influence of such a cascade on microstructure evolution.

As a way of accomplishing this objective, we used the RTNS-II to irradiate pure Copper specimens at 25,200 , and $400^{\circ} \mathrm{C}$ at doses of $3.6 \times 10^{18} \mathrm{n} / \mathrm{cm}^{2}$. We then examined the resulting damage structure by means of transmission electron microscopy.

We found that, at 25 and $200^{\circ} \mathrm{C}$, stacking fault tetrahedra (SFT), partially dissociated Frank loops, vacancy aggregates, and interstitial loops were nucleated by cascade collapse. All of these defects have a tendency to group together, with as many as 10 defects forming a single cluster. Because SFT are very stable under irradiation, excess interstitials (corresponding to the vacancies retained in the SFI') are accumulated in the matrix and form their own clusters. Interstitial loops that nucleate near a dislocation grow preferentially by absorbing the interstitials as they migrate toward the dislocation.

It is interesting to note that voids were created by dose irradiations as low as $1.0 \times 10^{18} \mathrm{n} / \mathrm{cm}^{2}$. The large number of vacancies retained in each void suggests that the voids have grcwn under irradiation by absorbing free vacancies. This process will play a very important role in void swelling at high doses.

\section{Defect-Structure Evolution after Radiation Damage from DT Fusion IVeutrons}

\author{
M. Kiritani \\ Faculty of Engineering, Hokkaido University, Sapporo 060, Japan
}

We have irradia :ed various metals at the RTNS-II and observed the resulting defect structures. Our purpose was to obta $\mathbf{n}$ a unified understanding of the defect-structure evolution associated with those irradiations which gentrate large cascades. We measured the maximum separation of interstitial atoms from the vacaney-sich zone, and found that (1) vacancy-type defect clusters create groups that reflect the damage caused by sub-cascades, and (2) high resolution stereo-electron microscopy discloses the threedimensional configuration of these sub-cascades. The effective collision cross-section needed to produce defect clusters was estimated, and the damage efficiency was obtained. it is possible to understand the roles of free interstitials released from cascade zones, the elimination of vacancy-clustered defects, and the formation of their own clusters, by comparing the defect structures of bulk specimens with those of thin foils that were removed from the bulk after irradiation.

This work was done in collaboration with $Y$. Shimomura and N. Yoshida. The low-temperature irradiation was performed in collaboration with M. W. Guinan. The author has given a more detajled description of this work at the First Infernational Conference on Fusion Reactor Materiats held in Tokyo (December, 1984). That report will be published in I. Nucl. Mat. 


\title{
14.8-MeV Neutron-Induced Activation in Some Metals and Practical Alloys
}

\author{
Keiji Saneyoshi
}

Department of Energy Sciences, Tokyo Institute of Technology, Nagatsuta, Yokohama 227, Japan

Katsutari Abe

The Research Institute for Iron, Steel, and Other Metals, Tohoku University, Sendai 980, Japan

We have measured the DT neutron cross sections for 41 reactions involving 15 elements that are of interest for fusion reactors. The measurement was performed using the activation method, with an error of less than $10 \%$. An intense neutron source and simultaneous irradiation reduced the statistical and systematic errors and lowered the irradiation time as well. We developed a computer code that uses these crosssection data to calculate dose rates from some practical irradiated alloys. The calculation agrees very woll with experimental results.

\section{Effects of 14-MeV Neutron Irradiation on SiC Fibers}

K. Okamura, T. Matsuzawa, arid M. Sato

The Oarai Branch, RIISOM, Tohoku Lniversity, Oarai, 15 wraki-ken 311-13, Japan

\author{
K. Sumita and T, lida \\ Department of Nuclear Engineering, Osäca University, Yamada-oka, Suita-shi, Osaka 565, Japan
}

$\mathrm{SiC}$ is one of the candidated materials for the first-wall of fusion reactors [1]. To examine the fearibility of $\mathrm{SiC}$ fibers for this purpose, we irradiated them with 14-MeV neutrons. Two types of fibers ware obtained, one by heating the polycarbosilane precursor fiber at $1000^{\circ} \mathrm{C}$, the oflerer at $1300^{\circ} \mathrm{C}$, in an $\mathrm{N}_{2} \mathrm{~g}$ as flow. The $1000^{\circ} \mathrm{C}$ fiber is in the amorphous state, and the $1300^{\circ} \mathrm{C}$ fiber is in the microcrystalline $3-\mathrm{SiC}$ state.

Both fibers were irradiated at RT NS-II (in the air at room temperatures) to fluences of about $4 \times 10^{17}$ $\mathrm{r} / \mathrm{cm}^{2}$. We made tensiie-strength tests and $\mathrm{x}$-ray diffracti in analyses of the neutron-irradiated $\mathrm{SiC}$ fibers so that we coull study the neutron-irradiation effects.

The results of these tests are given in the 1984 Antrual Research Report of Japanese Contributions for JapanUS Collaboration on RTNS-II Utilization (March, 1985), p. 106.

\section{Reference}

[1] L. H. Rovner and G. R Hapkins, Nıcl. Tecinlol. 29 (1976), p. 274. 
Fusion Experiments

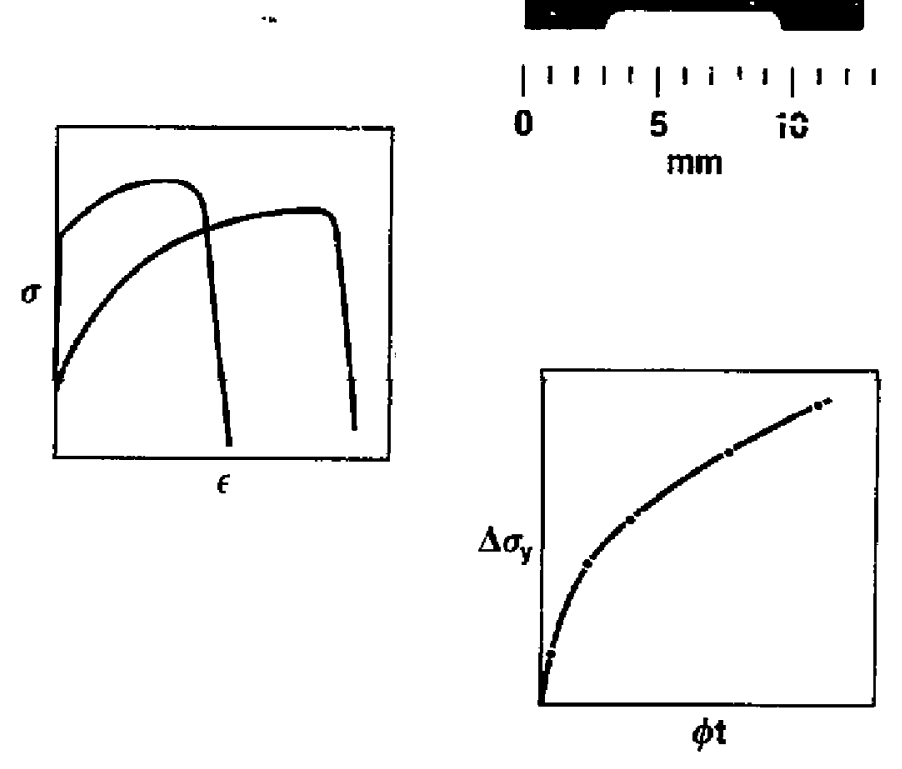




\title{
Permeation of ${ }^{13} \mathrm{~N}$-Labeled Gas Molecules Through Semi-Permeable Membranes
}

\author{
R. A. Jalbert \\ Los Alamos National Laboratory, Los Alamos, NM
}

The Los Alamos National Laboratory is developing an instrument for the Princeton Plasma Physics Laboratory that will both measure and differentiate the concentration of tritium in elemental and oxide forms. It will also analyze the concentration of the activated air that will be produced by the D-T neutrons of the Tokamak Fusion Test Reactor. The instrument will use semipermeable membrane driers to separate HTO from the other radioactive gases and will incorporate a catalyst to oxidize the HT to HTO. Tests at RTNS-II have indicated that the permeability of the ${ }^{13} \mathrm{~N}$ that was produced by D-T neutrons (presumably in the form of ${ }^{13} \mathrm{NO}_{\mathrm{x}}$ ) passing through the several driers tested was less than $0.1 \%$ of the permeability of HTO, which included Perma Pure Driers using Dupont Nafion capillary tubing along with commercial kidney dialyzers. Final testing of the complete, assembled instrument at RTNSG-II is planned for March, 1985, before we ship the instrument to Princeton.

A description of the instrument will be given at the American Nuclear Saciety National Topical Meetintg at Dayton, Ohio (April-May, 1985).

\section{Spinel Swelling after Low-Dose Neutron Irradiation}

\author{
W. A. Coghlan and F. W. Clinard, Jr. \\ Los Alamos National Laboratory, Los Alamos, NM \\ N. Iroh \\ Nagoya University \\ L. R. Greenwood \\ Argonne National Laboratory; Argonne, IL
}

As part of a fission- and fusion-neutron correlation study of ceramirs, we irradiated single-crystal sninel $\left(\mathrm{MgAl}_{2} \mathrm{O}_{4}\right)$ with fast-fission neutrons up to doses of $\left.8 \times 10^{18} \mathrm{n} / \mathrm{cm}^{2} ; \mathrm{E}>0.1 \mathrm{MeV}\right)$. Irracliations were carried out in the Omega West Reactor at roughly $50^{\circ} \mathrm{C}$. We found that swelling effectively saturated at about $2 \times 10^{13} \mathrm{n} / \mathrm{cm}^{2}$, corresponding to a damage level of only about $2 \times 10^{-3} \mathrm{dpa}$. These results imply that defects begin to interact by recombination, aggregation, or both at low damage levels in spinel. We are using rate equations to determine which of these linetic processes dominates. Results to date show that the observed swelling is consistent with the number of surviving defects calculated from these limiting cases, if swelling per Frenkel pair is taken to be 1 at.vol. Measurements of swelling from 14-MeVmeutron irradiation will be made at RTNS-II for comparison with these findings.

This work has been submitted for publication in the Seventh Antual Irogress Report on Special Purpose Mat:rials for Magnetically-Confined Fusion Reactors (DOE/ER 0113/4). 


\title{
Hardening of Instrument Channel Components for Fusion Radiation Environments
}

\author{
C. P. Cannon \\ Hanford Engineering Development Laboratory, Richland, WA
}

\begin{abstract}
Ceramic-to-metal seals are essential to many instrument channels. They are usually required to maintain hermeticity to $10^{-9}$ atm-cclHe, and their electrical properties must likewise remain unimpaired. Experience has shown that this type of component is vulnerable in hostile radiation environments, such as will be encountered in fusion applications. This experiment is designed to answer several key questions regarding fabrication parameters of ceramic-to-metal seals. Our purpose is thus to extend the base technology from which to design seals for $14-\mathrm{MeV}$ neutron environments.

A test package containing specially fabricated ceramic-to-metal seals has been prepared and is now being irradiated in RTNS-II. The seals were designed to evaluate the effects of the 14 MeV flux on the foliowing design parameters:

(i) ceramic purity, especially as influenced by trace impurities.

(ji) metallization paint.

(iii) selected geometrical factors.

Electrical properties affected by the irradiation are also being evaluated. The test objective-irradiation to $3 \times 10^{13} \mathrm{n}^{1 \mathrm{~cm}^{2}}$-is scheduled for completion by May 1985 .
\end{abstract}

\section{Fusion-Neutron Irradiation of $\mathrm{Nb}_{3} \mathrm{Sn}-\mathrm{Ti}$ Alloy Superconductors}

\author{
C. L. Snead, Jr. \\ Applied Science Department, Brookhaven National Laboratory (BNL), Brookhaven, NY \\ M. W. Guinan \\ Nuclear Chemistry Division, Lawrence Livermore National Laboratory, Livermoxe, CA
}

The purpose of this experiment is to make an initial assessment of the influence of titanium additions. on the irradiation response of five $\mathrm{Nb}_{3} \mathrm{Sn}$ alloys. One set of alloy samples will be irradiated at RTNS-Il, and an identical set will be irradiated to equivalent damage energies at the High Flux Beam Reactor (HFBR) at BNL.

The five alloy superconductors (which contained $0,0.5,1.0,2.0$, and 3.0 at. \% titanium) were prepared by the "bronze process." We formed the $\mathrm{Nb}_{3} \mathrm{Sn}$ layers through heat treatment at $725^{\circ} \mathrm{C}$ for $120 \mathrm{~h}$ in a vacuum that was voided to better than $10^{-5}$ torr. Twelve samples of each composition were separated into six packets (two wires of each composition) and then placed in a single irradiation package so that, at the end of the room-temperature srradiation, we might achieve fluences of $3.2,1.6,0.8,0.4,0.2$, and $0.1 \times 10^{18}$ $\mathrm{n} / \mathrm{cm}^{2}$,

The irradiation was carried out with that of C. Cannon and R. Flükiger (see p. of this annual re',ort). At the end of 1984, about one-third of the target dose had been achieved. We expect to finish the irradiation by March or April of 1985.

Following irradiation, measurements of $T_{c}$ will be carried out at LLNL on each of the sixty samples. After receiving the samples, Dr. Snead will measure their critical current density at 4.2 and $1.8 \mathrm{~K}$ at fields up to $24 \mathrm{~T}$ using the facilities of "ie National Magnet Laboratory at MIT. 


\title{
Measurement of 14-MeV Cross Sections
}

\author{
R. K. Smither and L. R. Greenwood \\ Argonne National Laboratory, Argonne, IL \\ D. G. Doran and H. L. Heinisch \\ Hanford Engineering Development Laboratories, Richland, WA
}

The object of this work is to measure the following reaction cross sections at 14.8-MeV-steutron energy: $\left.{ }^{94} \mathrm{Mo}(\mathrm{n}, \mathrm{P}){ }^{9} \mathrm{Nb},{ }^{94} \mathrm{Mo}(\mathrm{n}, 2 \mathrm{n}){ }^{93} \mathrm{Mo},{ }^{63} \mathrm{Cu}(n, p)\right)^{63} \mathrm{Ni}$, the sum of $\left.{ }^{54} \mathrm{Fe}(n, 2 \mathrm{n})\right)^{53} \mathrm{Fe}\left(\beta^{-}\right) \rightarrow{ }^{53} \mathrm{Mn}$ and ${ }^{54} \mathrm{Fe}(n, d){ }^{53} \mathrm{Mn}$. All of these reactions produce stable isotopes that could worsen the waste disposal problems of a fusion reactor. Little or no information is presently available on these cross sections, and measurements are complicated by the long lifetimes and the lack of characteristic gamma rays in the decay chain.

In this work a relatively new method, accelerator mass spectrometry (AMS), will be used to measure the concentration of the newly formed isotope in the sample. AMS makes a direct count of the rare atoms in a particle beam and compares this rate with that of a current bearn of the normal isotope. Such an approach circumvents the usual problems associated with long-]ived isotopes and with a shortage of countable gamma rays. We used separated isotope material (enriched to $92 \%{ }^{94} \mathrm{Mo}$ ) for the molybdenum sample in order to reduce the interference from other isotope products. All the other samples consisted of natural abundance.

- The inadiations at RT \$ $\$$ SS-11 have been completed and the samples are now being prepated for shipment to Argonne National L,aboratory where the mass spectroscopy will be completed.

\section{Low-Exposure Spectral-Effects Experiment}

\author{
H. L. Heinisch \\ Westinghouse Hanford Company, Richland, WA
}

We are planning to irradiate several miniature tlat tensile specimens of pure metais and alloys at elevated temperatures in RTNS-Il and the Omega West Reactor at Los Alamos National Laburatory. Our purpose is to study the effects of two very different neutron spectra on tensile properties and microstructures. The materials, Marz-grade copper, Marz-grade iron, AISI 316 stainless steel, and A302B pressure-vessel steel, constitute a representative sample of fusion-relevant face-centered cubic and body-centered cubic Inetals and alloys. They were chosen for their anticipated tensile sensitivity to very low exposures.

The first irradiation we performed was the joint US-Japan RTNS-II Experiment \$9. Specimens were irradiated simultaneously at 90 and $290^{\circ} \mathrm{C}$ usirg the HEDL dual-semperature vacuum-insilated furnace. On completion of the irradiation (September 23, 1984) we achieved a peak fluence of $2.4 \times 10^{18} \mathrm{n} / \mathrm{cm}^{2}$. The prime volume of the furnace (i.e., the first $6 \mathrm{~mm}$, over which the flux drops by about $65 \%$ ) was occupied by the tensile specimens for the HEDL Spectral-Effects Experiment, and the remaining volume was occupied by specimens of several other Japanese and US experimenters.

Tensile specimens for this experiment were also irradiated in the Japanese room-temperature irradiation. The miniature tensile specimens from both the Japanese and American irradiations are now being tested.

A more complete deseription of the Low.Exposure Spectral-Effects Experiment cart be found in the DAFS Quarterly Progress Report (January-Mardh, 1984), DOE/ER-0046/17, p. 76. 


\section{RTNS-II}

U.S.-Initiated

Non-Fusion Experiments

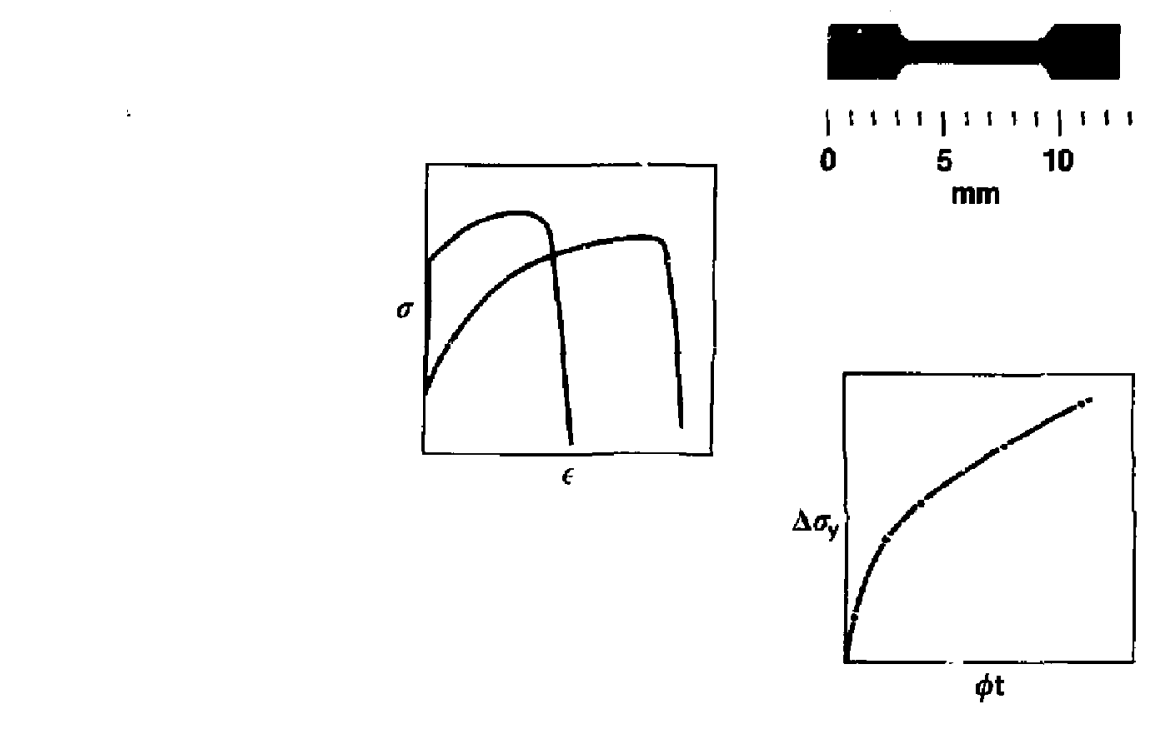

BEST AVAILABLE COPY 


\title{
An Intercomparison Exercise Using Irradiated Nickel Foils
}

\author{
R. C. Haight \\ Lawrence Livermore National Laboratory, Livermore, $\mathrm{CA}$
}

The International Atomic Energy Agency (iAEA) coordinates a number of nuclear-science research efforts under the title of Coordinated Research Programmes (CRP). One of these programs is devated to the measurement and analysis of 14-MeV neutron nuclear data needed for fission and fusion reactor technology. A major activity of this CRP is the measurement of activation cross sections. To ensure reliable gamma-ray counting of activated samples, we undertook an intercomparison exercise at RTNS-II in which we irradiateci a stack of 38 thin nickel foils of nearly equal source strength to yield 38 sources of ${ }^{57} \mathrm{C}{ }^{5},{ }^{58} \mathrm{Co}$, and ${ }^{60} \mathrm{Co}$. These foils were sent to the IAEA, and from there the $\%$ were distributed to participating laboratories in approximately 16 countries. The participants will measure the radioactivity of the foils and send their results back to the IAEA for compilation and comparison. Once this analysis is completed, we will publish our results as an IAEA document.

\section{Production of ${ }^{74} \mathrm{As},{ }^{77} \mathrm{Kr}$, and ${ }^{i 23} \mathrm{Xe}$ by (n,2n) Reactions: Cross Sections and Decay Properties}

\author{
r. Pawlikewski \\ U.S. Air Force \\ G. Coleman \\ Nebraska Wesleyan Untversity, LincoIn, NE \\ C. F. Smith \\ Lawrence Livermore National Laboratory, Livermose, CA
}

We irradiated sealed vials containing enriched ${ }^{78} \mathrm{Kr}$, ${ }^{24} \mathrm{Xe}$, and pure ${ }^{75} \mathrm{AsH}_{3}$ to produce ${ }^{7 \pi} \mathrm{Kr}$, ${ }^{123} \mathrm{Xe}$, and ${ }^{7}$ As by $(n, 2 n)$ reactions. By positioning the cells at angles between 30 and 90 deg to the beam, we were able to select neutron energies between 1.1.8 and $14.1 \mathrm{MeV}$ for the determination of excitation functions. We used aluminum and nickel monitor foils to determine neutron fluence energy. We performed radioassay by gamma-ray spectrometry without removing the gases from the vials. In this way we could obtain decay data for both the gaseous $(n, 2 n)$ products and their daughters. Four 1 th irradiations of five vials each were conducted.

The irradiations are as yet incomplete (four additional irradiations will be needed to provide the desired results). However, preliminary results have been published in an LLNL informal rejurit (UCAR10062). On completion of the experiments, the final results will appear in an LLNL formal report. 


\title{
Production of ${ }^{120 \mathrm{~m} S b}$
}

\author{
N. L. Smith \\ Nuclear Chemistry Division, Lawrence Livermore National Laboratory, Livermore, CA
}

A supply of the radioactive isotope ${ }^{120 m} \mathrm{Sb}$ (half-life 5.3 days) was prepared by the reaction

${ }^{121} \mathrm{SB}(\pi, 2 \pi)^{120 \mathrm{~m}} \mathrm{Sb}$.

The $220 \mathrm{~m} \mathrm{Sb}$ samples were then used to calibrate several of the $\mathrm{Ge}(\mathrm{Li})$ diode detectors operated by the Nuclear Chemistry Division.

There are no plans to publish this work.

\section{Residence-Time Distribution of Oil Shale Particles in a Fluidized Bed}

\author{
L. M. Lucht and D. NeIson \\ Lawrence Livermore National Laboratory, Livermore, CA
}

We used scintillation detecturs to measure the aver age time spent by particles of 1270, 12-20,20-40, and $40-70$ mesh in regions of a 7-inch-diameter fluidized bed of crushed oil shale. Small samples of each particle-size range were irradiated for ten minutes by a pneumatic transfer system using the radionuclide ${ }^{29} \mathrm{Al}$ (half-]ife $2.3 \mathrm{~min}$ ). We found that both particle size and rate of gas flow through the bed affect residence-time distributions.

Related work was done previously by Mallor and Christiansen [1] using a smaller diameter fluidized bed. Consequently; wall effects were siginfiratit and the mass-flow rate was about half that found in the experiments just completed.

\section{Reference}

[1] R. G. Mallon and D. E. Christiansen, "Median Residence and Dispersion Times for Fluidization of Crushed Oil Shale," Lawrence Livermore National Laboratory. Livermore, CA, UCRL-88492 (March, 1983). A ersion of this paper was also read at the 16ih Oil Shnle Symposimm held at Golden, CO (April, 1983).

\section{4-MeV Neutron Sensitivity of Uranium Fission-Based Neutron Detectors}

\author{
M. J. Moran and D. L. Redhead \\ Lawrence Livermore Na:ional Laboratory, Livermore, CA
}

We have conducted a series of experiments at RTNS-II to measure the 14-MeV-neutron sensitivity of vacuum-diode neutron detectors. These detectors teature either a Uranium-235 or U-238 cathode. When neutrons impinge on the detector, the resulting fission events induce a signal that is proportional to the charge ejected from the cathode by fission fragments. The sensitivities obtained in these measurements were comparable to the canonical sensitivities for these detectors. The results also agreed with sensitivities inferred from measurements using the thermal-neutron flux at the Pennsylvania State University's reactor facility. This group of experiments is cumplete and there is no intention to publish the measurements. 


\section{RTNS-II Foreign Experiments}
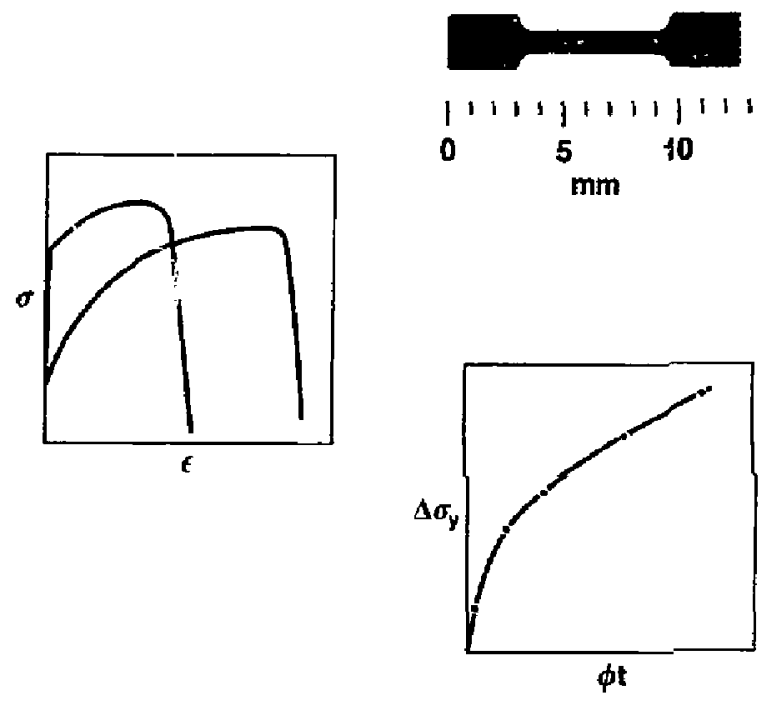


\title{
Fusion-Neutron Irradiation of Multifilamentary $\mathrm{Nb}_{3} \mathrm{Sn}$ Alloy Superconductors
}

\author{
R. Flükiger \\ Kernforshungszentrum, Postfach 3640, D-7500 Karlsruhe, Federal Republic of Germany \\ M. W. Guinan \\ Nuclear Chemistry Division, Lawrence Livermore National Laboratory, Livermore, CA
}

The purpose of this experiment is twofold: first, we plan to investigate the possiblt effects of filament size on tadiation degradation, and, secondly; we intend to compare the radiation response of unalloyed $\mathrm{Nb}_{3} \mathrm{Sn}$ with that of three other alloys.

The samples are all "bronze process" conductors. One of the two unalloyed samples contains 19 filaments and the other, 10,000. Three alloys are included in the experiment, two of which contain 19 filaments and are alloyed with $0.6 \%$ nickel and $1,6 \%$ titanium. The third contains $61 \times 61$ filaments and is alloyed with $7.0 \%$ tantalum.

Six samples of each conductor were packaged and mounted with respect to the target so that fluences of $3.2,1.6,0.8,0.4,0.2$, and $0.1 \times 10^{18} n^{\prime} \sin ^{2}$ would be delivered at the and of the irradiation. The experiment is combined with those of Cannon, Snead, and Guinan (sce $p$. of this annual report).

At the end of 1984, about one-third of the desired fuence had been attained. We expect to complete the irradiation in March or April, 1985. After a one-montk cooling period, the critical temperature $\left(T_{c}\right)$ of all 30 samples will be measured at LLNL and the samples will be shipped to Karlsruhe for critical current density (je) reasuremer.ts as a function of both strain and field. Dr. Flükiger will use the Grenoble facilities to carry out $\mathrm{j}_{\varepsilon}$ nieasurements to $24 \mathrm{~T}$. 


\title{
Neutron Irradiation of Superconductors and the Damage-Energy Conicept for Scaling Neutron Spectra
}

\author{
P. A. Hahn and H. W. Weber \\ Atominstitut der Österreichischer Universitaten, A-1070 Wien, Austria \\ M. W. Guinan \\ Nuclear Chemistry Division, Lawrence Livermore National l.aboratory, Livermore, CA \\ L. R. Greenwood, R. C. Birtcher, and B. S. Brown \\ Materials Science Division, Argonne National Laboratory, Argonne, IL
}

Various stabilized single-core and multifilamentary $\mathrm{NbT}$ i superconductors, including the Swiss Large Coil Test (LCT) conductor, have been irradiated at room temperature at the RTNS-Il in three nuns up to a total fluence of $5.1 \times 10^{17} \mathrm{n} / \mathrm{cm}^{2}$ of monoenergetic $14.5-\mathrm{MeV}$ neutrons. After each irradiation, we determined the critical current density $\left(\hat{i}_{\mathrm{c}}\right)$ in the range between 1.0 and $8.0 \mathrm{~T}$. This determination was accomplished at $4.2 \mathrm{~K}$ with a standard four-probe technique and a $50-\mu \mathrm{V} / \mathrm{cm}$ voltage criterimn.

Identical sets of these materials have been irradiated under similar conditions with a spallation neutron spectrum of the Intense Pulsed Neutron Source (IPNS) in Argonne up to a fluence of $1.9 \times 10^{13} \mathrm{n}^{\mathrm{cm}} \mathrm{cm}^{2}$ $\left(E_{n}>0.1 \mathrm{MeV}\right)$ and in the IPIGA-Mark II reactor in Vienna [1].

After a careful source characterization of these three irradiation facilities, the damage-energy cross section, $E_{j}$, was calculated for four different types of $\mathrm{NbTi}$ alloy $(42,46,49$, and $54 \mathrm{wt} \%$ titanium) $[2,3]$. The radiation-jnduced degradation of $\mathrm{j}_{\mathrm{c}}$ js found to scale (within experimental uncertainties) with the appropriate damage-energy cross sections multiplied by the fluence. As an example, Fig. 1 plots the fractional change of $j_{6}$ of two commercial multifilamentary conductors versus the average damage energy displaced peratom.

This first explicit proof of the damage-energy concept for $j_{\ell}$ variations in superconductors is considered to be most useful for the evaluation of radiation damage in superconductors under fusion reartor conditions.

The influence of the neutron s'rectrum in modifying the various flux pinning mechanisms operating in these materials has been analyzed in a Ph. D. dissertation by Peter Hahn [4]; an abstract of this study has been submitted to the Infernational Cryogenic Ma!eriais Conjerence, to be held in Boston in 1985.

\section{References}

[1] F. Nardai, H. W. Weber, and R. K. Majx: Cryogenics 21 (1981), p. 223.

[2] L. R. Greenwood: ]. Nucl. Mat. 108 \& 109 (1982), p. 21.

[3] R. C. Birtcher, T. H. Blewitt, M. A. Kirk, T. L. Scott, B. S. Brown, and L. R. Greenwood: ]. Nucl. Mat. 108 \& 109 (1982), p. 3.

[4] P. A. Fahn: Ph. D. Dissertation, Technical University Vienna (1984), unpublished. 


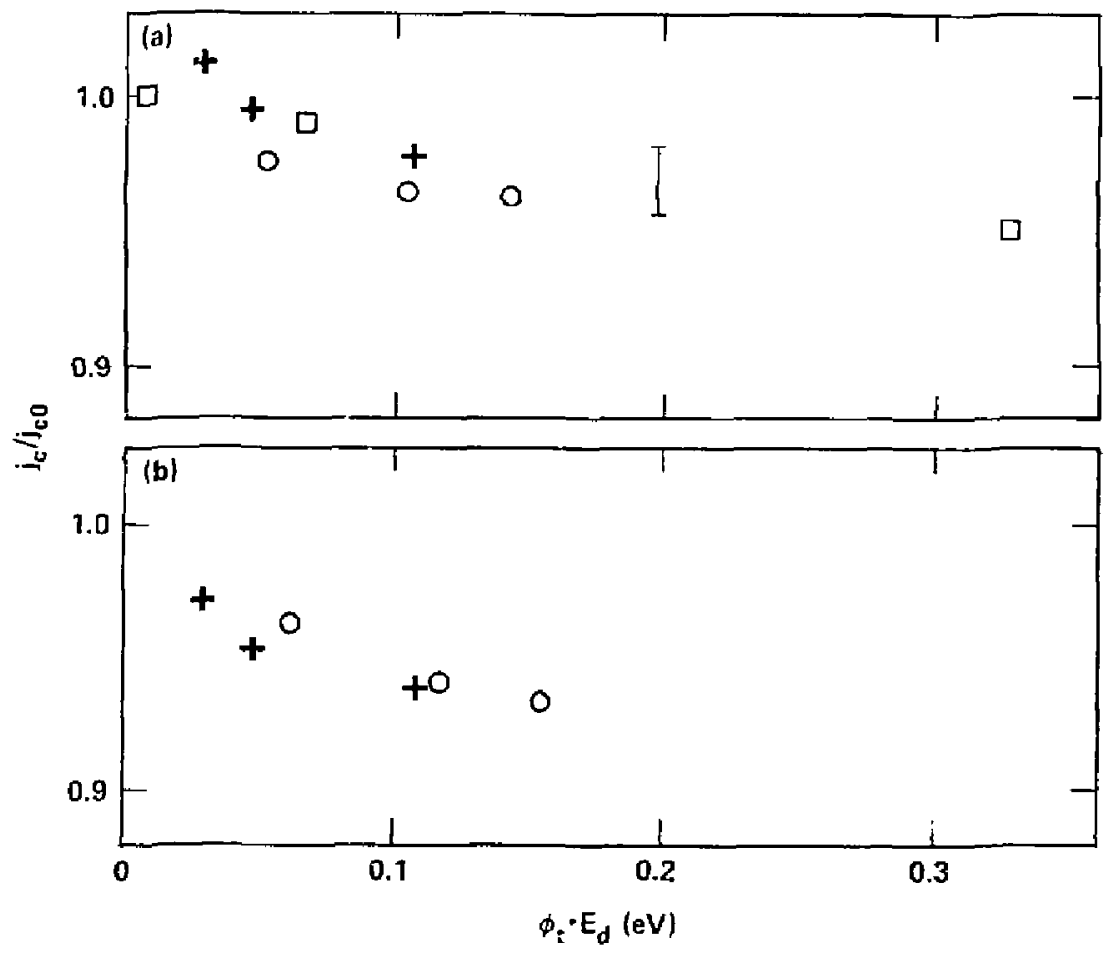

Figure 1. Fractional change of $j_{\varepsilon}$ at $5.0 \mathrm{~T}$ as a function of the average damage energy displaced per atom $\left(\phi t \times E_{d}\right.$ ) for two $N b T i$ multifilamentary conductors: (a) $\mathrm{Nb}, 49 \mathrm{wt} \% \mathrm{Ti}$, and (b) the Swiss LCT conductor ( $N b, 46.5 \mathrm{wt} \% \mathrm{~T} j$ ). A representative error bar is showri in the upper data set (a).

$+=$ irradiation with spallation neutrons al IPNS,

o =irradiation with 14.5-MeV neutror:s at RTNS-II,

$\square=$ irradiation in the TRIGA-Mark II reactor, Vienna. 